\title{
Association between cardiovascular disease, cardiovascular drug therapy, and in-hospital outcomes in patients with COVID-19: data from a large single-center registry in Poland
}

\author{
Michał Terlecki', Wiktoria Wojciechowska', Marek Klocek', Agnieszka Olszanecka', Katarzyna Stolarz-Skrzypek', \\ Tomasz Grodzicki², Maciej Małecki³, Barbara Katra ${ }^{3}$, Aleksander Garlicki', Monika Bociąga-Jasik4, \\ Krzysztof Sładek5, Andrzej Matyja ${ }^{6}$, Jerzy Wordliczek7, Agnieszka Słowik, Tomasz Mach', Katarzyna Krzanowska10, \\ Marcin Krzanowski1 ${ }^{10}$, Paweł Stręk¹, Piotr Chłosta12, Piotr Hydzik'13, Mariusz Korkosz ${ }^{14}$, Tadeusz Popiela15, \\ Maciej Pilecki ${ }^{16}$, Artur Gądek ${ }^{17}$, Marek Rajzer ${ }^{1}$
}

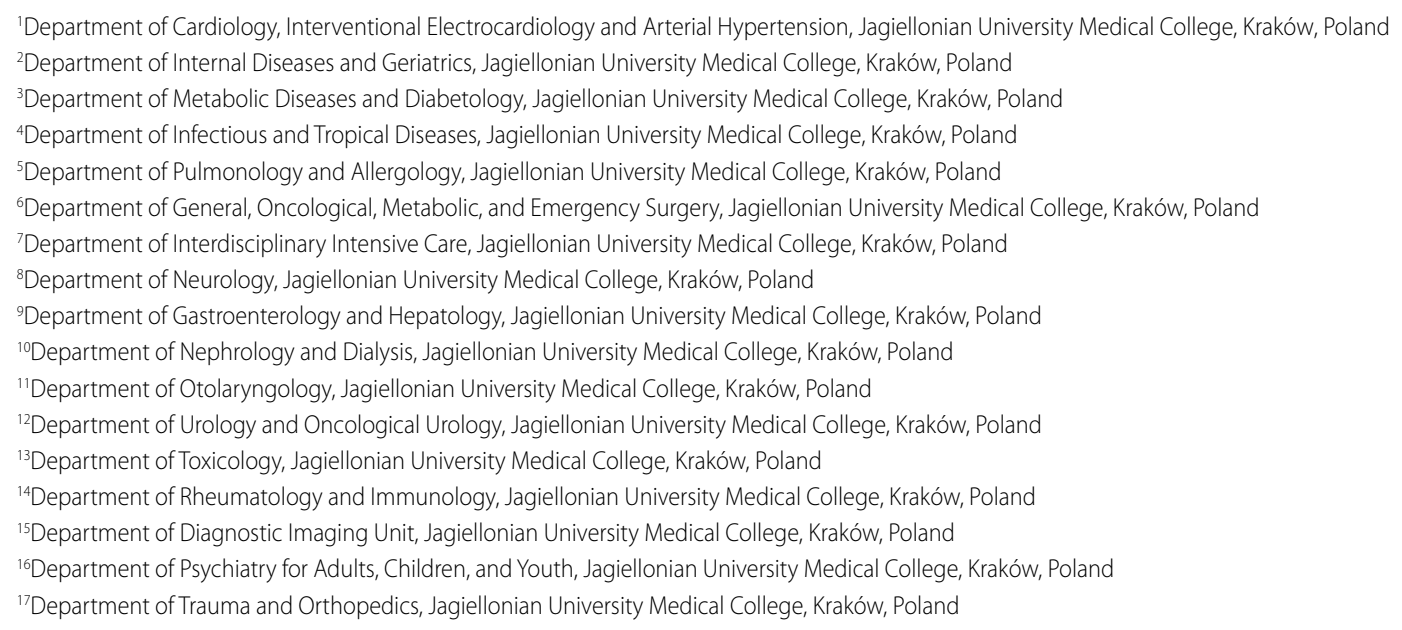

\section{Editorial}

by Tadic et al.,

see p. 730

Correspondence to: Prof. Marek Rajzer MD, PhD,

$1^{\text {st }}$ Department of Cardiology, Interventional Electrocardiology and Arterial Hypertension, Jagiellonian University Medical College, Jakubowskiego 2, 30-688 Kraków, Poland, phone: +48124002150, e-mail: marek.rajzer@ uj.edu.pl Copyright by the Author(s), 2021

Kardiol Pol. 2021. 79 (7-8): 773-780; DOI: 10.33963/KP.15990 Received:

February 16, 2021 Revision accepted: April 26, 2021 Published online: April 29, 2021

\section{A B S TR A C T}

Background: The coronavirus disease 19 (COVID-19) recently became one of the leading causes of death worldwide, similar to cardiovascular disease (CVD). Coexisting CVD may influence the prognosis of patients with COVID-19.

Aims: We analyzed the impact of CVD and the use of cardiovascular drugs on the in-hospital course and mortality of patients with COVID-19.

Methods: We retrospectively studied data for consecutive patients admitted to our hospital, with COVID-19 between March $6^{\text {th }}$ and October $15^{\text {th }}, 2020$.

Results: 1729 patients (median interquartile range age 63 [50-75] years; women 48.8\%) were included. Overall, in-hospital mortality was $12.9 \%$. The most prevalent CVD was arterial hypertension (56.1\%), followed by hyperlipidemia (27.4\%), diabetes mellitus (DM) (25.7\%), coronary artery disease (16.8\%), heart failure (HF) (10.3\%), atrial fibrillation (13.5\%), and stroke (8\%). Angiotensin-converting enzyme inhibitors or angiotensin receptor blockers (ACEIs/ARBs) were used in $25.0 \%$ of patients, $\beta$-blockers in $40.7 \%$, statins in $15.6 \%$, and antiplatelet therapy in $19.9 \%$. Age over 65 years (odds ratio [OR], $6.4 ; 95 \%$ $\mathrm{Cl}$, 4.3-9.6), male sex (OR, 1.4; $95 \% \mathrm{Cl}, 1.1-2.0)$, pre-existing $\mathrm{DM}(\mathrm{OR}, 1.5 ; 95 \% \mathrm{Cl}, 1.1-2.1)$, and $\mathrm{HF}(\mathrm{OR}, 2.3$; 
$95 \% \mathrm{Cl}, 1.5-3.5)$ were independent predictors of in-hospital death, whereas treatment with ACEIs/ARBs $(\mathrm{OR}, 0.4 ; 95 \% \mathrm{Cl}, 0.3-0.6)$, $\beta$-blockers (OR, 0.6; $95 \% \mathrm{Cl}, 0.4-0.9)$, statins $(\mathrm{OR}, 0.5 ; 95 \% \mathrm{Cl}, 0.3-0.8)$, or antiplatelet therapy $(\mathrm{OR}, 0.6 ; 95 \% \mathrm{Cl}: 0.4-0.9)$ was associated with lower risk of death.

Conclusions: Among cardiovascular risk factors and diseases, HF and DM appeared to increase in-hospital COVID-19 mortality, whereas the use of cardiovascular drugs was associated with lower mortality. Key words: COVID-19, cardiovascular disease, cardiovascular drugs, in-hospital mortality

Kardiol Pol 2021; 79, 7-8: 773-780

\section{INTRODUCTION}

Since the WHO declared coronavirus disease 19 (COVID-19) a global pandemic in March 2020, more than 144500000 people worldwide (2 700000 in Poland) have been affected, with approximately 3000000 fatal cases (64 000 in Poland) [1]. COVID-19 is currently one of the leading causes of mortality in many countries, with the number of deaths similar to those from cardiovascular disease (CVD) or cancer [1, 2].

The relation between the severity of the COVID-19 disease course and concomitant CVD is being studied worldwide; however, no large reports from Poland have yet been published. Many studies in other countries have confirmed that patients with pre-existing CVD or cardiovascular risk factors had worse COVID-19 outcomes [3-5]. The aforementioned data come mostly from non-European countries and meta-analyses of small observational studies with heterogeneous definitions of CVD. The frequency of cardiovascular risk factors and CVD among patients hospitalized due to COVID-19 is similar to that observed in the general population, but there is a disproportionately higher frequency of CVD among non-survivors of COVID-19 [3-6]. It is uncertain whether this finding is incidental or secondary to differences in age and sex distribution, or if there is an association between CVD and higher mortality in patients with COVID-19. Another problem is the lack of uniform standards for COVID-19 diagnosis, hospitalization, and therapy between countries. Therefore, differences in therapeutic models for COVID-19 may influence final outcomes, including the association between COVID-19 mortality and CVD. The impact of cardiovascular drugs on the clinical course of COVID-19 has also not yet been determined. At the beginning of the pandemic, the biggest controversies involved angiotensin-converting enzyme inhibitors and angiotensin receptor blockers (ACEls/ARBs), as it has been hypothesized that these drugs may increase susceptibility to infection by SARS-CoV-2 and promote viral replication, subsequently worsening the disease course and outcomes $[7,8]$. However, this hypothesis has not been confirmed in consecutive studies on mortality in COVID-19 [8-11]. Currently, there are limited data on prognosis for patients with COVID-19 being treated with other cardiovascular drugs such as $\beta$-blockers, statins, or antiplatelet therapy.

The purpose of this study was to analyze the impact of CVD and selected cardiovascular drugs on the course of hospitalisation and mortality of patients with COVID-19.

\section{METHODS}

We retrospectively studied the medical records of all consecutive patients who were admitted to the University Hospital in Kraków (which was converted temporarily into an infectious disease hospital dedicated to COVID-19 treatment) between March 6, 2020, and October 15, 2020. Patients were admitted from the whole Małopolska Voivodship and neighboring regions. Thus, our study cohort may be assumed to be representative of the whole macro-region. Patients were diagnosed with COVID-19 according to WHO and Polish guidelines with the use of RT-PCR [12-14]. The treatment algorithm for COVID-19 was in accordance with the recommendations of the Polish Association of Epidemiologists and Infectiologists [13, 14]. Patient data were obtained from the Hospital Information System. Cardiovascular risk factors and CVD were identified based on a medical history of prehospital diagnosis and/or treatment and defined according to current European Society of Cardiology guidelines [15]. The analyzed endpoints in

WHAT'S NEW?

We present results based on a large database of patients with COVID-19 treated in a single hospital according to the same standard. Our study cohort was representative of the population of the south-east macro-region of Poland. We analyzed the impact of cardiovascular disease and pharmacological treatment for cardiovascular disease on in-hospital outcomes in patients with COVID-19. The findings support existing evidence that advanced age, male sex, diabetes mellitus, and pre-existing heart failure are major predictors of poor outcomes in patients with COVID-19. We did not identify any potential harmful association between angiotensin-converting enzyme inhibitors (ACEls) or angiotensin receptor blockers (ARBs) and unfavorable prognosis in patients with COVID-19, but we provided new evidence that the use of cardiovascular drugs (including ACEls/ARBs, $\beta$-blockers, statins, and antiplatelet therapy) is associated with reduced mortality. 
our study were: in-hospital mortality from any cause, need for treatment in the intensive care unit (ICU), non-invasive oxygen therapy, mechanical ventilation, length of hospital stay, and length of ICU stay. We also analyzed the use of cardiovascular drugs grouped into drug classes ( $\beta$-blockers, ACEls/ARBs, statins, and antiplatelet therapy). The study was approved by the Jagiellonian University Ethics Committee, decision number 1072.6120.278.2020.

\section{Statistical analysis}

We used the SAS software, version 9.2 (SAS Institute, Cary, NC, USA), for database management and statistical analysis. The results were expressed as numerical values and percentages for categorical variables and mean values and standard deviation (SD) if parametric (assessed using the Kolmogorov-Smirnov test) or median and interquartile range (IQR) for continuous variables. To test the differences between survivors and non-survivors in means and proportions we applied the t-test and the chi-square statistic, respectively while in the case of nonparametric data, the Wilcoxon Signed Rank test were used. Using multivariable logistic regression, we searched for possible covariates of the likelihood of in-hospital death or the use of oxygen therapy. Then odds ratios (OR) and corresponding 95\% confidence intervals $(95 \% \mathrm{Cl})$ were calculated for covariates influencing in-hospital death. To investigate factors determining prolonged hospitalisation (after log-transformation) the linear regression was implemented. We used Kaplan-Meier method to estimate survival curves among patients with established cardiovascular diseases, and the difference between survival curves for patients treated versus untreated with cardiovascular drugs during hospitalization were assessed with the log rank tests. In all analyses a $P$-value of 0.05 or less was considered statistically significant.

\section{RESULTS}

\section{Study population}

From March 6, 2020 to October 15, 2020, 1729 patients were admitted to the University Hospital in Kraków due to COVID-19 and completed their hospital course (i.e. from admission to discharge or death). Our study population included 843 women (median age [IQR], 64 [51-77] years) and 886 men (median age [IQR], 62 [50-74] years). In our sample, 950 (55\%) patients were over 65 years of age.

The most prevalent cardiovascular risk factor was arterial hypertension (56.1\%), followed by hyperlipidemia (27.4\%) and diabetes mellitus (25.7\%) (Table 1). The most common CVD were coronary artery disease $(16.8 \%$ of patients), heart failure (10.3\%), atrial fibrillation (13.5\%), and a history of stroke (8\%); $2.8 \%$ of patients had a previously implanted cardiac pacemaker or implantable cardioverter defibrillator (Table 1).

The median hospitalization length was 16 days (Table 2). Admission to the ICU was needed in 194 patients with a median length of ICU stay of 9 days. The overall in-hospital mortality was $12.9 \%$ (223 of 1729 patients), and $81 \%$ of non-survivors were older than 65 years (180 of 223 patients).

Of 1729 patients, $25.0 \%$ were treated with an ACEIs/ARBs, $40.7 \%$ with a $\beta$-blocker, $15.6 \%$ with a statin, and $19.9 \%$ with an antiplatelet drug (Table 2 ).

\section{Comparison of survivors with non-survivors}

Tables 1 and 2 summarize the clinical characteristics of survivors and non-survivors, including risk factors and pre-existing diseases, use of medication, and results of medical tests at the time of admission. As compared to survivors, non-survivors were older, predominantly male, and had a higher prevalence of arterial hypertension, dia-

Table 1. Basic characteristic of participants

\begin{tabular}{|c|c|c|c|c|}
\hline Characteristics & $\begin{array}{c}\text { All } \\
(n=1729)\end{array}$ & $\begin{array}{l}\text { Survivors } \\
(n=1506)\end{array}$ & $\begin{array}{l}\text { Non-survivors } \\
\quad(n=223)\end{array}$ & P-value ${ }^{a}$ \\
\hline Age, years, median (IQR) & $63(50-75)$ & $61.0(49-72)$ & $78(69-84)$ & $<0.001$ \\
\hline Female, n (\%) & $843(48.8)$ & 749 (49.7) & $94(42.1)$ & 0.034 \\
\hline $\mathrm{BMI}^{\mathrm{b}}, \mathrm{kg} / \mathrm{m}^{2}$, mean $(\mathrm{SD})$ & $28.5(5.04)$ & $28.6(4.86)$ & $28.3(6.15)$ & 0.64 \\
\hline \multicolumn{5}{|l|}{ Pre-existing conditions, n (\%) } \\
\hline Arterial hypertension & $970(56.1)$ & $813(53.9)$ & $157(70.4)$ & $<0.001$ \\
\hline Hyperlipidemia & $473(27.4)$ & $408(27.1)$ & $65(29.1)$ & 0.52 \\
\hline Diabetes mellitus & $445(25.7)$ & $361(24.0)$ & $84(37.7)$ & $<0.001$ \\
\hline Coronary artery disease & $290(16.8)$ & $223(14.8)$ & $67(30.0)$ & $<0.001$ \\
\hline Heart failure & $179(10.3)$ & $121(8.0)$ & $58(26.0)$ & $<0.001$ \\
\hline Atrial fibrillation & $233(13.5)$ & $175(11.6)$ & $58(26.0)$ & $<0.001$ \\
\hline Cardiac pacing ${ }^{c}$ & $49(2.8)$ & $36(2.4)$ & $13(5.8)$ & 0.004 \\
\hline Stroke & $139(8.0)$ & $110(7.3)$ & $29(13.0)$ & 0.003 \\
\hline Asthma & $106(6.1)$ & $97(6.4)$ & $9(4.0)$ & 0.16 \\
\hline COPD & $89(5.1)$ & $72(4.8)$ & $17(7.6)$ & 0.07 \\
\hline
\end{tabular}

Data are presented as mean (SD), median (interquartile range [IQR]) or number (\%).

aFor the difference between survivors and non-survivors. ${ }^{b}$ Data available in 697 patients. ${ }^{c}$ Cardiac pacing including any type of implantable device.

Abbreviations: BMI, body-mass index; COPD, chronic obstructive pulmonary disease; SD, standard deviation 
Table 2. Clinical characteristics and drug therapy among survivors and non-survivors

\begin{tabular}{|c|c|c|c|c|}
\hline Characteristics & $\begin{array}{c}\text { All } \\
(n=1729)\end{array}$ & $\begin{array}{l}\text { Survivors } \\
(\mathrm{n}=1506)\end{array}$ & $\begin{array}{l}\text { Non-survivors } \\
(n=223)\end{array}$ & $P$-value ${ }^{a}$ \\
\hline \multicolumn{5}{|l|}{ Parameters on admission } \\
\hline $\mathrm{SBP}^{\mathrm{b}}, \mathrm{mm} \mathrm{Hg}$, mean (SD) & $132.3(21.3)$ & $133.5(19.9)$ & $124.4(27.7)$ & $<0.001$ \\
\hline $\mathrm{DBP}$ b, $\mathrm{mm} \mathrm{Hg}$, mean (SD) & $81.3(14.1)$ & $82.5(13.1)$ & $73.1(16.6)$ & $<0.001$ \\
\hline Heart rate $/ \mathrm{min}$, mean (SD) & $83(14.7)$ & $83.3(13.9)$ & $86.9(19.2)$ & 0.003 \\
\hline Respiratory rate $/ \mathrm{min}$, median (IQR) & $14(12-16)$ & $14(12-16)$ & $16(14-22)$ & $<0.001$ \\
\hline Oxygen saturation ${ }^{\mathrm{b}}, \%$, median (IQR) & $96(94-97)$ & $96(94-97)$ & $94(89-96)$ & $<0.001$ \\
\hline hsCRPc, mg/l, median (IQR) & $36.9(9.7-84.0)$ & $30.1(8.1-72.5)$ & $93.7(47.4-184.0)$ & $<0.001$ \\
\hline D-dimer', mg/l, median (IQR) & $0.77(0.46-1.48)$ & $0.70(0.44-1.25)$ & $1.59(0.93-3.13)$ & $<0.001$ \\
\hline $\mathrm{IL} 6, \mathrm{pg} / \mathrm{ml}^{\mathrm{b}}$, median (IQR) & $23.9(6.4-63.2)$ & $18.2(4.7-46.4)$ & $76.1(36.2-166.8)$ & $<0.001$ \\
\hline NT-proBNPb, pg/ml, median (IQR) & 594 (169-2199) & $376(133-1416)$ & 3399 (1019-8147) & $<0.001$ \\
\hline hs cTn, ng/ml, median (IQR) & $10.6(5.2-32.9)$ & $8.6(4.7-20.9)$ & $44.1(17.6-165.7)$ & $<0.001$ \\
\hline Creatinine, $\mu \mathrm{mol} / \mathrm{l}$, median (IQR) & $76.9(63.4-96.9)$ & $74.6(62.4-91.2)$ & $111.0(80.9-173)$ & $<0.001$ \\
\hline \multicolumn{5}{|l|}{ Cardiovascular therapy, n (\%) } \\
\hline ACEI & $315(18.9)$ & $281(19.4)$ & $34(15.8)$ & 0.21 \\
\hline ARB & $124(7.2)$ & $119(7.9)$ & $5(2.24)$ & 0.002 \\
\hline ACEI/ARB & $433(25.0)$ & $395(26.2)$ & $38(17.0)$ & 0.003 \\
\hline$\beta$-blocker & $703(40.7)$ & $604(40.1)$ & $99(44.4)$ & 0.22 \\
\hline Antiplatelet therapy ${ }^{d}$ & $344(19.9)$ & $298(19.8)$ & $46(20.6)$ & 0.78 \\
\hline Statin & $269(15.6)$ & $237(15.7)$ & $32(14.3)$ & 0.59 \\
\hline \multicolumn{5}{|l|}{ Clinical course } \\
\hline Non-invasive oxygen therapye $\mathrm{n}(\%)$ & $465(26.89)$ & $332(22.05)$ & $133(59.64)$ & $<0.001$ \\
\hline Mechanical ventilation, $\mathrm{n}(\%)$ & $154(8.91)$ & $48(3.19)$ & $106(47.53)$ & $<0.001$ \\
\hline Admission to ICU, $\mathrm{n}(\%)$ & $194(11.2)$ & $86(5.71)$ & $108(48.43)$ & $<0.001$ \\
\hline Length of ICU stay, days, median (IQR) & $9(5-16)$ & $9.5(5-18)$ & $8(4-14)$ & 0.22 \\
\hline Length of hospital stay, days, median (IQR) & $16(11-25)$ & $20.2(13.1)$ & $11(6-17)$ & $<0.001$ \\
\hline
\end{tabular}

Data are presented as mean (SD), median (IQR), or number (\%).

aFor the difference between survivors and non-survivors. 'Data available in 1443 patients for SBP and DBP, 715 patients for NT-pro BNP, 1440 patients for D-dimer, 718 patients for IL6, 1397 patients for oxygen saturation, 1384 patients for heart rate, and 1231 patients for respiratory rate. chsCRP mean (SD): all = 63.2 (75.7); survivors = 53.7 (65.9); non-survivors = $123.6(101.9)$. ${ }^{\mathrm{A} A n t i p l a t e l e t ~ t h e r a p y ~ i n c l u d e d ~ t h o s e ~ t r e a t e d ~ w i t h ~ l o w-d o s e ~ a s p i r i n ~ o r / a n d ~ c l o p i d o g r e l, ~ t i c a g r e l o r, ~ o r ~ p r a s u g r e l . ~}{ }^{\circ} \mathrm{At}$ least $5 \mathrm{I} / \mathrm{min}$.

Abbreviations: ACEl, angiotensin-converting enzyme inhibitor; ARB, angiotensin receptor blocker; DBP, diastolic blood pressure; hsCRP, highly sensitive C-reactive protein; hs cTn, high-sensitivity cardiac troponin; ICU, intensive care unit; IL6, interleukin 6; NT-proBNP, N-terminal pro-brain natriuretic peptide; SBP, systolic blood pressure; SD, standard deviation

betes mellitus, coronary artery disease, heart failure, atrial fibrillation, stroke, and use of cardiac pacing.

The frequency of cardiovascular drug use did not differ between survivors and non-survivors, with the exception of ACEls/ARBs, which were less commonly used by the latter group.

The median hospitalization length was shorter, and the need for ICU admission more common, in non-survivors than in survivors (Table 2). Compared to survivors, patients who died during hospitalization had significantly lower blood pressure and oxygen saturation values, higher heart and respiratory rates, and higher levels of immune-inflammatory and cardiac biomarkers on admission $(P \leq 0.003)$.

\section{Predictors of in-hospital death}

Based on the multivariable logistic regression model, independent predictors of higher risk of in-hospital death from any cause were: age over 65 years, male sex, pre-existing diabetes mellitus, and a history of heart failure, whereas treatment with ACEls/ARBs, $\beta$-blockers, statins, or antiplatelet therapy corresponded with a lower risk of death (Figure 1).

Based on Kaplan-Meier method the survival probability in patients with CVD was substantially higher among those treated with ACEls/ARBs, $\beta$-blockers, or statins (Figure 2).

Additional analysis was performed to assess predictors of in-hospital death in treated and not treated groups of patients. In 771 participants who were not treated during hospitalization with $\beta$-blockers, ACEls, sartan, statin or antiplatelet drugs 94 (12.2\%) died. In this group in multivariable logistic regression an older age $(\mathrm{OR}, 8.01 ; 95 \% \mathrm{Cl}$, 4.58-13.33), male gender (OR, 2.58; 95\% Cl, 1.48-4.65), and history of hypertension (OR, 2.25; $95 \% \mathrm{Cl}, 1.26-3.98)$, heart failure (OR, 6.10; 95\% Cl, 2.06-19.83), or atrial fibrillation (OR $3.15,95 \% \mathrm{Cl}, 1.18-8.47)$ were associated with higher risk of in-hospital death. Among participants treated with any of aforementioned class of cardiovascular drugs ( $n=958)$, 829 (86.5\%) survived. In analyses of in-hospital death, age above 65 years (OR, 3.72 95\% Cl, 2.22-6.53) and history of heart failure (OR, 1.94; 95\% Cl, 1.20-3.12) were associated with higher risk, while history of hypertension (OR, 0.48; $95 \% \mathrm{Cl}, 0.30-0.78$ ) with lower risk of in-hospital death.

The analysis of the model in which cardiovascular drug were not taken into account an age above 65 years (OR, 5.3; $95 \% \mathrm{Cl}, 3.7-7.9)$, male sex (OR, 1.48; 95\% Cl, 1.09-2.00), and history of heart failure (OR, 2.14; $95 \% \mathrm{Cl}, 1.43-3.20)$ were associated with higher risk of in hospital mortality. 


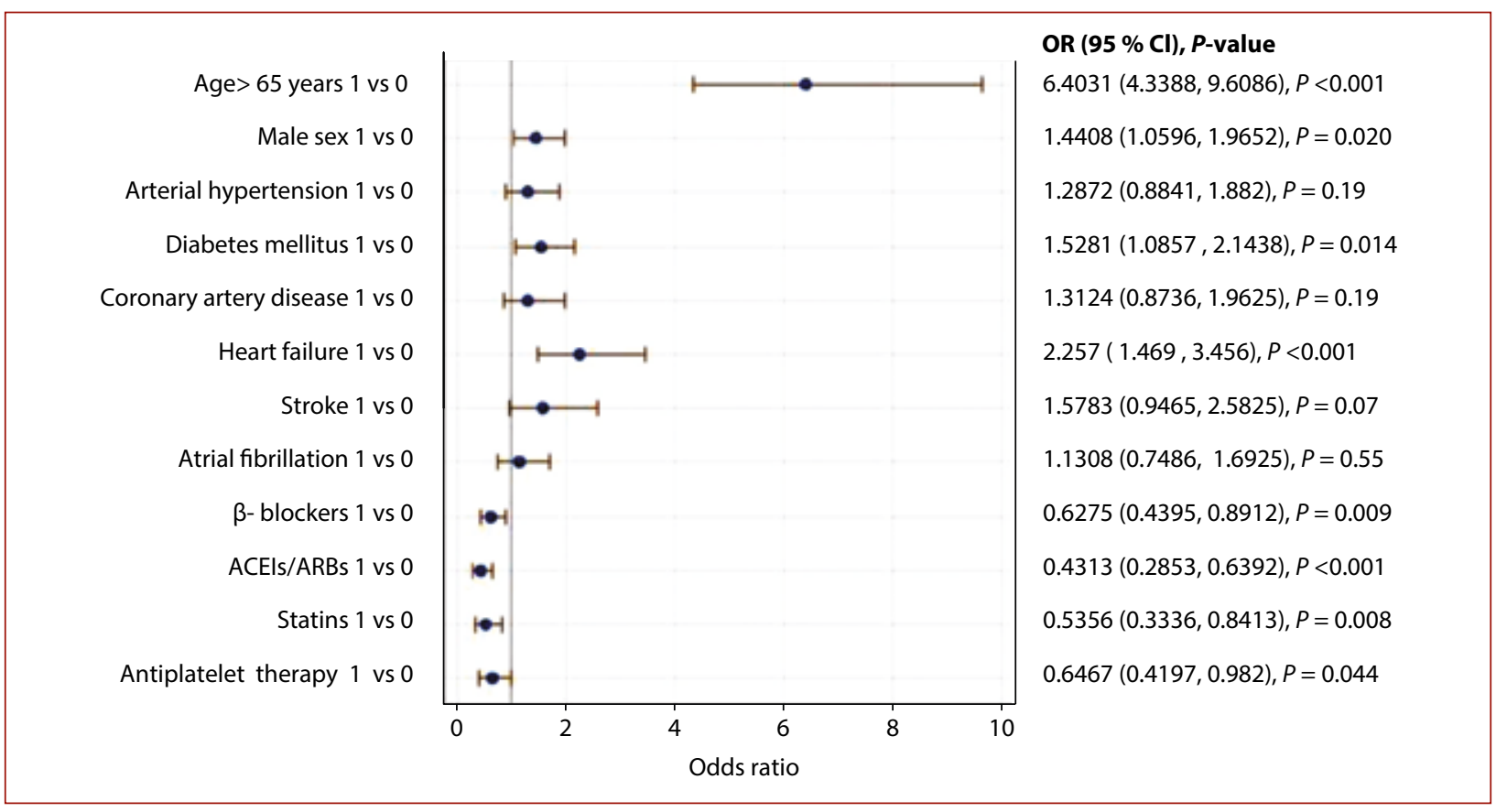

Figure 1. Multivariable logistic regression analysis

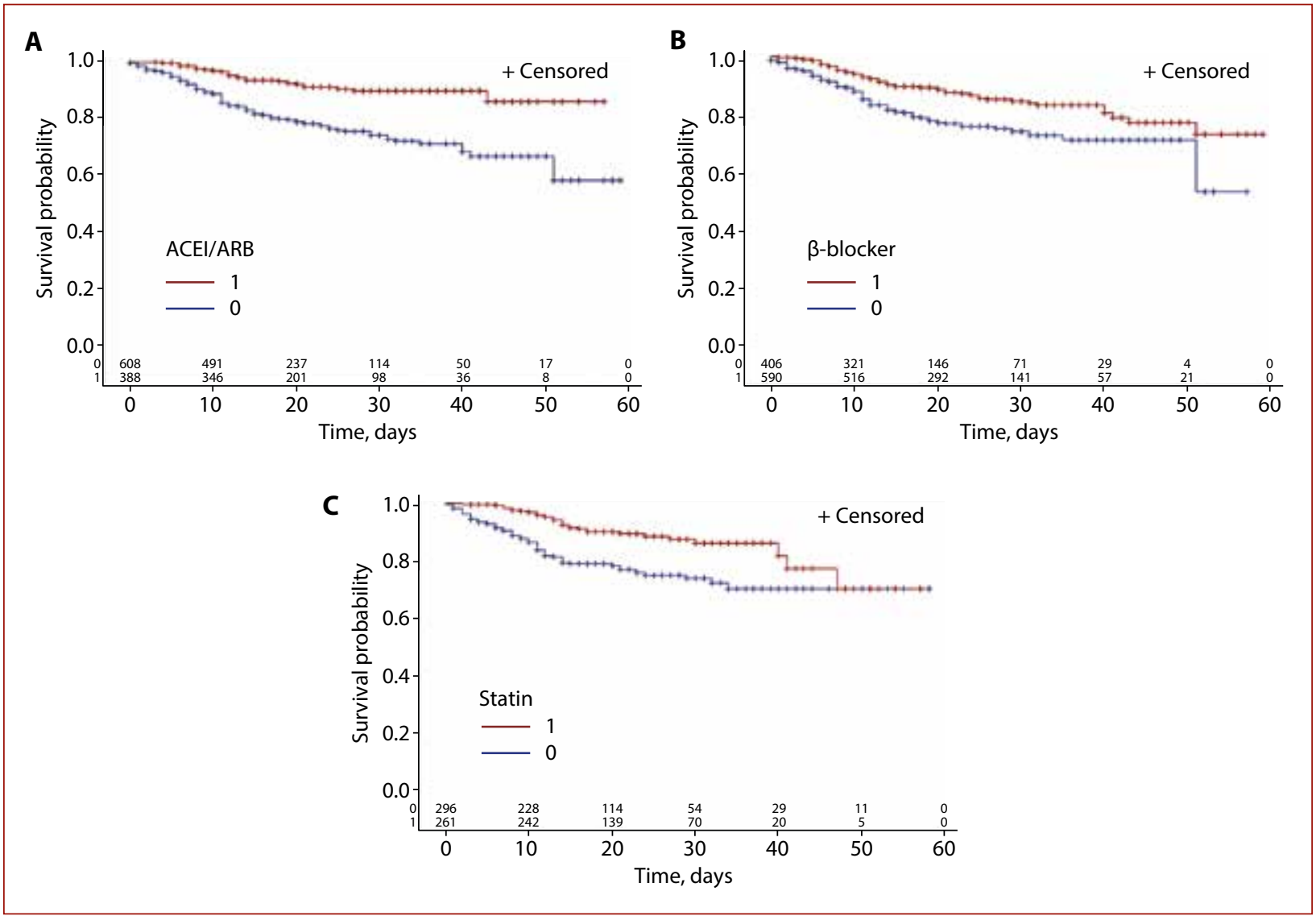

Figure 2. A. Survival probability among participants diagnosed with arterial hypertension, coronary artery disease, or heart failure by angiotensin-converting enzyme inhibitor or angiotensin receptor blocker (ACEI/ARB) use. Red line indicates ACEI/ARB treatment; blue line indicates lack of ACEI/ARB treatment. TIME, days of in-hospital stay. Log rank $P<0.001$. B. Survival probability among participants diagnosed with arterial hypertension, coronary artery disease, or heart failure by $\beta$-blocker use. Red line indicates $\beta$-blocker treatment; blue line indicates lack of $\beta$-blocker treatment. TIME, days of in-hospital stay. Log $\operatorname{rank} P<0.001$. C. Survival probability among participants diagnosed with coronary artery disease or hyperlipidemia by statin use. Red line indicates statin treatment; blue line indicates lack of statin treatment. TIME, days of in-hospital stay. Log rank $P<0.001$ 
Table 3. Other outcomes in survivors, analyzed using a linear regression model for length of hospitalization and a logistic regression model for oxygen therapy

\begin{tabular}{|c|c|c|c|c|}
\hline \multirow{3}{*}{ Outcome } & \multirow{3}{*}{$\frac{\text { Risk factors }}{\text { 0 vs } 1}$} & \multicolumn{3}{|c|}{ Model } \\
\hline & & \multirow{2}{*}{$\begin{array}{c}\text { R-square } \mathbf{0 . 1 4} \\
\text { Parameter estimate }\end{array}$} & \multicolumn{2}{|c|}{$P=0.001$} \\
\hline & & & Standard error & $P$-value \\
\hline \multirow[t]{13}{*}{ Length of hospitalization } & Age $>65$ years & 0.12 & 0.02 & $<0.001$ \\
\hline & Male sex & 0.05 & 0.01 & 0.001 \\
\hline & Arterial hypertension & 0.04 & 0.02 & 0.034 \\
\hline & Diabetes mellitus & 0.05 & 0.02 & 0.004 \\
\hline & $\begin{array}{c}\text { Coronary artery } \\
\text { disease }\end{array}$ & -0.03 & 0.02 & 0.24 \\
\hline & Heart failure & 0.02 & 0.03 & 0.34 \\
\hline & Atrial fibrillation & 0.02 & 0.03 & 0.40 \\
\hline & Stroke & -0.01 & 0.02 & 0.52 \\
\hline & $\beta$-blocker & 0.06 & 0.02 & 0.001 \\
\hline & ACEI/ARB & 0.05 & 0.02 & 0.012 \\
\hline & Statin & 0.02 & 0.02 & 0.38 \\
\hline & Antiplatelet therapy & 0.02 & 0.02 & 0.28 \\
\hline & 0 vs 1 & OR estimate & \multicolumn{2}{|c|}{$95 \% \mathrm{Cl}$} \\
\hline \multirow[t]{12}{*}{ Oxygen therapy } & Age $>65$ years & 1.73 & \multicolumn{2}{|c|}{$1.29-2.32$} \\
\hline & Male sex & 1.96 & \multicolumn{2}{|c|}{$1.52-2.53$} \\
\hline & Arterial hypertension & 1.26 & \multicolumn{2}{|c|}{$0.92-1.74$} \\
\hline & Diabetes mellitus & 1.13 & \multicolumn{2}{|c|}{$0.83-1.52$} \\
\hline & Coronary artery disease & 0.96 & \multicolumn{2}{|c|}{$0.65-1.39$} \\
\hline & Heart failure & 0.92 & \multicolumn{2}{|c|}{$0.57-1.47$} \\
\hline & Atrial fibrillation & 0.92 & \multicolumn{2}{|c|}{$0.61-1.38$} \\
\hline & Stroke & 1.20 & \multicolumn{2}{|c|}{$0.75-1.88$} \\
\hline & $\beta$-blocker & 1.21 & \multicolumn{2}{|c|}{$0.89-1.63$} \\
\hline & ACEI/ARB & 0.93 & \multicolumn{2}{|c|}{$0.68-1.25$} \\
\hline & Statin & 0.84 & \multicolumn{2}{|c|}{$0.58-1.21$} \\
\hline & Antiplatelet therapy & 1.01 & \multicolumn{2}{|c|}{$0.70-1.45$} \\
\hline
\end{tabular}

Abbreviations: $\mathrm{ACEl}$, angiotensin-converting enzyme inhibitor; $\mathrm{ARB}$, angiotensin receptor blocker; $\mathrm{Cl}$, confidence interval; $\mathrm{OR}$, odds ratio

\section{Other outcomes}

Table 3 shows the results of the multivariable linear regression and multivariable logistic regression analysis. Older age, male sex, history of diabetes mellitus, arterial hypertension, and treatment with $\beta$-blockers or ACEls/ARBs were independent predictors of longer length of hospital stay due to COVID-19. Age over 65 years and male sex were associated with a higher risk of requiring oxygen therapy.

\section{DISCUSSION}

We present the data on the impact of CVD and cardiovascular drugs on in-hospital COVID-19 outcomes based on, to our knowledge, one of the largest single-center databases of COVID-19 patients in Poland [16, 17]. We confirm that pre-existing cardiovascular comorbidities and drug therapy have an impact on outcomes in patients hospitalized due to COVID-19. In our study, non-survivors were older, predominantly male, and had a higher prevalence of arterial hypertension, diabetes mellitus, coronary artery disease, heart failure, atrial fibrillation, and stroke than survivors. Moreover, we found that, beyond older age and male sex, diabetes mellitus and heart failure were independent predictors of in-hospital death from any cause. Importantly, we confirmed the beneficial effect of ACEls/ARBs, $\beta$-block- ers, statins, and antiplatelet therapy on survival in patients with indications for those drugs.

A higher percentage of men and individuals aged over 65 years among non-survivors in our cohort is consistent with previous reports, indicating that older age and male sex are independent risk factors for COVID-19 mortality [9, 16-18]. We have also found that, among survivors, male sex and older age were associated with requiring oxygen therapy and a longer hospital stay. The relationship between advanced age and worse prognosis in COVID-19 can be explained by a higher frequency of comorbidities, a hampered immune response with aging, and an increased susceptibility to secondary infection during hospitalization [18]. There are many hypotheses explaining sex differences in the clinical course of COVID-19, including: genetic, hormonal, immune, and behavioral factors, the distribution of cardiovascular risk factors, and differences in angiotensin-converting enzyme 2 (ACE2) expression on the cell surface [19].

Previous studies confirmed that CVD is an independent risk factor for death in patients with COVID-19 [6, 9, 20]. It is well known that the prevalence of CVD and metabolic diseases increases with age [21]. In our cohort, only heart failure and diabetes mellitus were independently associated with mortality in patients with COVID-19, which is 
in accordance with the results of other studies [9, 16, 22]. Increased mortality in patients with COVID-19 with pre-existing heart failure is not surprising due to the well-known impact of chronic heart failure on reducing life expectancy [23]. Similarly to our observation, diabetes mellitus has been found to be independently associated with the severity of COVID-19 and increased COVID-19 mortality [22, 24]. Moreover, the presence of typical macrovascular complications (including heart failure and coronary artery disease) and microvascular complications (i.e. chronic kidney disease) of diabetes mellitus increases COVID-19 mortality $[22,24]$. In agreement with our work, arterial hypertension was one of the most prevalent pre-existing CVD in patients with COVID-19 in previous studies [9, 20] However, data about the relationship between arterial hypertension and COVID-19 mortality are inconclusive $[9,17]$. We did not confirm the influence of arterial hypertension on in-hospital mortality.

In our study the prevalence of cardiovascular drug treatment did not differ between survivors and non-survivors, with the exception of ACEls/ARBs, which were less commonly prescribed in non-survivors than in survivors. Moreover, we found that in-hospital use of ACEls/ARBs is associated with a reduced probability of death (OR 0.42). It is an important observation that the aforementioned agents are not harmful, but may be fundamental for the protection of patients with CVD during the COVID-19 pandemic [8].

Our study also underlines the relationship between $\beta$-blocker use and mortality in COVID-19. Some previous studies showed that exposure to $\beta$-blockers reduced mortality in septic shock and improved outcomes in patients with respiratory failure $[25,26]$. It has been hypothesized that in severely ill patients activation of the adrenergic system leads to activation of the renin-angiotensin-aldosterone system and over-expression of ACE2 receptors, which may facilitate entry of SARS-CoV-2 into host cells, leading to a more severe presentation of COVID-19 [27]. $\beta$-blockers may therefore reduce host cell entry by the virus and reduce the catecholamine-dependent inflammatory over-response [27]. This hypothesis needs further research.

The third group of cardiovascular drugs that we found to be associated with altered COVID-19 mortality were statins. In a study of 8910 patients with COVID-19, Mehra et al. [9] noted that in-hospital statin use reduced mortality. In our registry, patients treated with statins also had a lower risk of in-hospital death (OR, 0.49).

In contrast to anticoagulant therapy, only a few observational studies have previously been reported regarding the protective or therapeutic effects of antiplatelet therapy in COVID-19, especially regarding aspirin use before and during hospitalization [28]. Due to the fact that SARSCoV-2 infection leads to diffuse endothelial inflammation and dysfunction, which triggers platelet adhesion and aggregation [29], some authors claimed that there is a rationale to stabilize the endothelium and platelets during viral replication, with antiplatelet as well as anti-inflammatory therapy [30]. The results we have obtained seem to support this point of view.

For all analyzed cardiovascular drugs, the key finding from our study is a positive influence on survival in patients with COVID-19. Hence, these drugs should not be withdrawn unless absolutely necessary.

The length of hospital stay in our cohort (median 16 days) confirms that COVID-19 is a serious illness requiring long treatment. Compared to survivors, patients who died had a worse clinical condition on admission and during their hospital stay. This is in accordance with other studies $[3-6,16,17]$. We therefore think that, in our cohort, the severity of clinical COVID-19 presentation on admission had a significant impact on the length of hospital stay.

Our study has several limitations and the results should be considered with caution. Firstly, the retrospective study design limits the ability to obtain complete data for patients' characteristics; however, we presented a large, comprehensive dataset of patients and checked the data carefully. Secondly, the retrospective nature of the study did not allow us to draw conclusion about cause-effect relationship.

\section{CONCLUSIONS}

Our findings expand the previous evidence that advanced age, male sex, diabetes mellitus, and pre-existing heart failure are major predictors of poor outcomes in patients with COVID-19. The negative influence of pre-existing CVD on prognosis in patients with COVID-19 could be mitigated by in hospital use of cardiovascular drugs.

\section{Article information}

Conflict of interest: None declared.

Funding: This publication was supported by the National Center for Research and Development CRACoV-HHS project (Model of multi-specialist hospital and non-hospital care for patients with SARSCoV-2 infection) through the initiative "Support for specialist hospitals in fighting the spread of SARSCoV-2 infection and in treating COVID-19" (contract number SZPITALE-JEDNOIMIENNE/18/2020). The described research was implemented by consortium of the University Hospital in Cracow and the Jagiellonian University Medical College.

Open access: This article is available in open access under Creative Common Attribution-Non-Commercial-No Derivatives 4.0 International (CC BY-NC-ND 4.0) license, allowing to download articles and share them with others as long as they credit the authors and the publisher, but without permission to change them in any way or use them commercially. For commercial use, please contact the journal office at kardiologiapolska@ptkardio.pl.

How to cite: Terlecki M, Wojciechowska W, Klocek M, et al. Association between cardiovascular disease, cardiovascular drug therapy, and in-hospital outcomes in patients with COVID-19: data from a large single-center registry in Poland. Kardiol Pol. 2021; 79(7-8): 773-780, doi: 10.33963/KP.15990.

\section{REFERENCES}

1. Dong E, Du H, Gardner L. An interactive web-based dashboard to track COVID-19 in real time. Lancet Infect Dis. 2020; 20(5): 533-534, doi: 10.1016/S1473-3099(20)30120-1, indexed in Pubmed: 32087114.

2. Woolf SH, Chapman DA, Lee JH. COVID-19 as the leading cause of death in the United States. JAMA. 2021; 325(2): 123-124, doi: 10.1001/jama.2020.24865, indexed in Pubmed: 33331845. 
3. Richardson S, Hirsch JS, Narasimhan M, et al. the Northwell COVID-19 Research Consortium. Presenting characteristics, comorbidities, and outcomes among 5700 patients hospitalized with COVID-19 in the New York City area. JAMA. 2020;323(20):2052-2059, doi: 10.1001/jama.2020.6775, indexed in Pubmed: 32320003.

4. Inciardi RM, Adamo M, Lupi L, et al. Characteristics and outcomes of patients hospitalized for COVID-19 and cardiac disease in Northern Italy. Eur Heart J. 2020; 41(19): 1821-1829, doi: 10.1093/eurheartj/ehaa388, indexed in Pubmed: 32383763.

5. Zhou F, Yu T, Du R, et al. Clinical course and risk factors for mortality of adult inpatients with COVID-19 in Wuhan, China: a retrospective cohort study. Lancet. 2020; 395(10229): 1054-1062, doi: 10.1016/S0140-6736(20)305663, indexed in Pubmed: 32171076.

6. Grasselli G, Zangrillo A, Zanella A, et al. COVID-19 Lombardy ICU Network. Baseline characteristics and outcomes of 1591 patients infected with SARS-CoV-2 admitted to ICUs of the Lombardy Region, Italy. JAMA. 2020; 323(16): 1574-1581, doi: 10.1001/jama.2020.5394, indexed in Pubmed: 32250385.

7. Fang L, Karakiulakis G, Roth $M$. Are patients with hypertension and diabetes mellitus at increased risk for COVID-19 infection? Lancet Respir Med. 2020; 8(4): e21, doi: 10.1016/S2213-2600(20)30116-8, indexed in Pubmed: 32171062.

8. Kreutz R, Algharably EAH, Azizi M, et al. Hypertension, the renin-angiotensin system, and the risk of lower respiratory tract infections and lung injury: implications for COVID-19. Cardiovasc Res. 2020; 116(10): 1688-1699, doi: 10.1093/cvr/cvaa097, indexed in Pubmed: 32293003.

9. Mehra MR, Desai SS, Kuy S, et al. Cardiovascular disease, drug therapy, and mortality in covid-19. N Engl J Med. 2020; 382(25): e102, doi: 10.1056/NEJMoa2007621, indexed in Pubmed: 32356626.

10. Zhong $Y$, Zhao $L, W u ~ G$, et al. Impact of renin-angiotensin system inhibitors use on mortality in severe COVID-19 patients with hypertension: a retrospective observational study. J Int Med Res. 2020; 48(12): 300060520979151, doi: 10.1177/0300060520979151, indexed in Pubmed: 33322988.

11. Mancia G, Rea F, Ludergnani $M$, et al. Renin-angiotensin-aldosterone system blockers and the risk of covid-19. N Engl J Med. 2020; 382(25): 2431-2440, doi: 10.1056/NEJMoa2006923, indexed in Pubmed: 32356627.

12. World Health Organization. Laboratory testing for coronavirus disease (COVID-19) in suspected human cases. Interim guidance 19 March 2020. https://apps.who.int/iris/bitstream/handle/10665/331501/WHO-COVID-19-laboratory-2020.5-eng.pdf?sequence=1\&isAllowed=y (February 16, 2021).

13. Flisiak R, Horban A, Jaroszewicz J, et al. Management of SARS-CoV-2 infection: recommendations of the Polish Association of Epidemiologists and Infectiologists as of March 31, 2020. Pol Arch Intern Med. 2020; 130(4): 352-357, doi: 10.20452/pamw.15270, indexed in Pubmed: 32231173.

14. Flisiak R, Horban A, Jaroszewicz J, et al. Management of SARS-CoV-2 infection: recommendations of the Polish Association of Epidemiologists and Infectiologists. Annex no. 1 as of June 8, 2020. Pol Arch Intern Med. 2020; 130(6): 557-558, doi: 10.20452/pamw.15424, indexed in Pubmed: 32529822.

15. European Society of Cardiology. Guidelines and Scientific Documents. www.escardio.org (February 16, 2021).

16. Yang J, Zheng $Y$, Gou $X$, et al. Prevalence of comorbidities and its effects in patients infected with SARS-CoV-2: a systematic review and meta-analysis. Int J Infect Dis. 2020; 94: 91-95, doi: 10.1016/j.jijid.2020.03.017, indexed in Pubmed: 32173574.
17. Hessami A, Shamshirian A, Heydari K, et al. Cardiovascular diseases burden in COVID-19: systematic review and meta-analysis. Am J Energ Med. 2020: S0735-6757(20)30908-6, doi: 10.1016/j.ajem.2020.10.022, indexed in Pubmed: 33268238.

18. Mueller AL, McNamara MS, Sinclair DA. Why does COVID-19 disproportionately affect older people? Aging (Albany NY). 2020; 12(10): 9959-9981, doi: 10.18632/aging.103344, indexed in Pubmed: 32470948.

19. Sama IE, Ravera A, Santema BT, et al. Circulating plasma concentrations of angiotensin-converting enzyme 2 in men and women with heart failure and effects of renin-angiotensin-aldosterone inhibitors. Eur Heart J. 2020; 41(19): 1810-1817, doi: 10.1093/eurheartj/ehaa373, indexed in Pubmed: 32388565.

20. Lippi G, Wong J, Henry BM. Hypertension in patients with coronavirus disease 2019 (COVID-19): a pooled analysis. Pol Arch Intern Med. 2020; 130(4): 304-309, doi: 10.20452/pamw.15272, indexed in Pubmed: 32231171.

21. Joseph P, Leong D, McKee M, et al. Reducing the global burden of cardiovascular disease, part 1: the epidemiology and risk factors. Circ Res. 2017; 121(6): 677-694, doi: 10.1161/CIRCRESAHA.117.308903, indexed in Pubmed: 28860318.

22. Barron E, Bakhai $C$, Kar $P$, et al. Associations of type 1 and type 2 diabetes with COVID-19-related mortality in England: a whole-population study. Lancet Diabetes Endocrinol. 2020; 8(10): 813-822, doi: 10.1016/S22138587(20)30272-2, indexed in Pubmed: 32798472.

23. Ponikowski P, Voors AA, Anker SD, et al. ESC Scientific Document Group. 2016 ESC guidelines for the diagnosis and treatment of acute and chronic heart failure: the task force for the diagnosis and treatment of acute and chronic heart failure of the European Society of Cardiology (ESC) developed with the special contribution of the Heart Failure Association (HFA) of the ESC. Eur Heart J. 2016; 37(27): 2129-2200, doi: 10.1093/eurheartj/ehw128, indexed in Pubmed: 27206819.

24. Holman N, Knighton P, Kar P, et al. Risk factors for COVID-19-related mortality in people with type 1 and type 2 diabetes in England: a population-based cohort study. Lancet Diabetes Endocrinol. 2020; 8(10): 823-833, doi: 10.1016/S2213-8587(20)30271-0, indexed in Pubmed: 32798471.

25. Tan K, Harazim M, Tang B, et al. The association between premorbid beta blocker exposure and mortality in sepsis-a systematic review. Crit Care. 2019; 23(1): 298, doi: 10.1186/s13054-019-2562-y, indexed in Pubmed: 31484576.

26. Al-Qadi MO, Kashyap R. Effect of chronic beta blockers use on sepsis-related acute respiratory distress syndrome. Am J Respir Crit Care Med. 2015; 191: A1602.

27. Vasanthakumar N. Beta-adrenergic blockers as a potential treatment for COVID-19 patients. Bioessays. 2020; 42(11): e2000094, doi: 10.1002/bies.202000094, indexed in Pubmed: 32815593.

28. Chow JH, Khanna AK, Kethireddy S, et al. Aspirin use is associated with decreased mechanical ventilation, intensive care unit admission, and in-hospital mortality in hospitalized patients with coronavirus disease 2019. Anesth Analg. 2021; 132(4): 930-941, doi: 10.1213/ANE.0000000000005292, indexed in Pubmed: 33093359.

29. Varga Z, Flammer AJ, Steiger $P$, et al. Endothelial cell infection and endotheliitis in COVID-19. Lancet. 2020; 395(10234): 1417-1418, doi: 10.1016/S0140-6736(20)30937-5, indexed in Pubmed: 32325026.

30. Godino C, Scotti A, Maugeri N, et al. Antithrombotic therapy in patients with COVID-19? Rationale and evidence. Int J Cardiol. 2021; 324: 261-266, doi: 10.1016/j.ijcard.2020.09.064, indexed in Pubmed: 33002521. 